\title{
Effects of magnesium pemoline on avoidance behavior in rats'
}

\author{
R. F. RITZMANN, LOREN MILLER, ${ }^{2}$ and R. W. BELL, \\ Northern Illinois University,DeKalb, Ill. 60115
}

Following oral injections of either 0,5 , or $20 \mathrm{mg} / \mathrm{kg}$ of magnesium pemoline mixed with tragacanth in an equal volume solution, 60 Long-Evans hooded rats were given 70 trials in a two-compartment one-way avoidance apparatus. Type of CS (light vs buzzer) and interval between drug injection and conditioning $(30$ vs $60 \mathrm{~min})$ were varied factorially with drug dosage. Ss receiving either 5 or $20 \mathrm{mg} / \mathrm{kg}$ of magnesium pemoline performed significantly better than did controls, independent of the other two variables. These results fail to support the Beach \& Kimble (1967) hypothesis that the major effects of magnesium pemoline on avoidance conditioning are due to an increased aversile responsiveness to a buzzer CS, which has typically been employed in studies of the drug, rather than directly affecting the avoidance learning.

Recent studies have shown that magnesium pemoline increases the acquisition and retention of an avoidance response in rats (Plotnikoff, 1966), presumably through stimulating the synthesis of brain RNA polymerases (Glasky \& Simon, 1966). A possible artifact, preventing any clear-cut interpretation of the differences in learning, has been suggested by Beach \& Kimble (1967). In a partial replication of the Plotnikoff (1966) study they found that rats injected intraperitoneally with magnesium pemoline avoided a buzzer (CS) associated with shock (UCS) more frequently than did controls and displayed shorter response latencies in an active avoidance task. However, they failed to find differences in shock-avoidance. In subsequent experiments which measured activity changes and responsiveness to the buzzer alone, it was found that magnesium pemoline caused a lesser decrease in activity level and a more sustained responsiveness to the buzzer's sound than did control injections of tragacanth. The authors concluded that this increased responsiveness to the buzzer may account for the latency differences observed in the avoidance task.

In studies investigating the effects of magnesium pemoline on avoidance conditioning a buzzer-shock paradigm has been consistently employed. If the Beach and Kimble hypothesis is correct, utilization of a nonauditory $\mathrm{CS}$ in the avoidance task should eliminate the augmenting effects of magnesium pemoline on response latencies to the CS. The present study is a test of that hypothesis.

\section{EXPERIMENTAL DESIGN AND SUBJECTS}

The experimental design was a 2 by 2 by 3 by 7 factorial design. The variables were Type of CS (light vs buzzer), Interval between drug injection and conditioning (30 vs $60 \mathrm{~min})$, Dosage of drug $(0,5$, or $20 \mathrm{mg} / \mathrm{kg}$ of magnesium pemoline mixed with tragacanth in an equal volume solution), and Blocks of Trials (seven days, 10 trials daily). Ss were 60 Long-Evans hooded rats, 36 females and 24 males. All Ss were experimentally naive, and ranged in age from 90 to 120 days at the beginning of the experiment. Five Ss, three male and two female, were assigned to each of the independent treatment conditions.

\section{APPARATUS}

The apparatus was a two-compartment one-way avoidance apparatus, constructed of white Marlite with a grid floor. Each compartment measured $15 \times 13 \times 16$ in. Separating the two compartments was a vertically-opening door, which was operated by a motor and electro-magnet mounted on top of the apparatus. The two CSs were a $71 / 2-\mathrm{W}$ bulb mounted on the back wall of the starting compartment and a 75-dB buzzer mounted on top of the starting compartment. A switch mounted outside the apparatus selected the appropriate CS. A remote switch initiated each trial. The switch simultaneously activated the $\mathrm{CS}$, opened the door separating the two compartments, and activated a Foringer interval timer which controlled UCS onset (CS-UCS interval was $4 \mathrm{sec}$ ). The grid floor was activated by a LVE 1531 shock-scrambler. A Sylvania PCK-10 photoconductor was mounted in the wall adjacent to the center door to detect $S$ 's response and control the door closing, shock offset, and a Standard .01-sec timer, used to record response latency.

\section{PROCEDURE}

Subjects were given daily oral injections of the specified drug and dosage either $30 \mathrm{~min}$ or $60 \mathrm{~min}$ prior to starting the avoidance conditioning. Following the appropriate delay, individual Ss were placed in the starting chamber of the conditioning apparatus and permitted to explore for $2 \mathrm{~min}$ at which time $E$ initiated the trial. Following each trial the $S$ remained in the escape compartment for $30 \mathrm{sec}$ and was then returned to the starting compartment for $15 \mathrm{sec}$ before initiating the next trial. Mean response latency and number of avoidance responses per daily block of 10 trials was recorded for each $\mathrm{S}$.

\section{RESULTS}

Mean daily latencies were transformed to running speeds via a reciprocal transformation.

Number of avoidance responses and mean running speeds per block of trials were separately analyzed as 2 by 2 by 3 by 7 analyses of variances. The results of the analyses are identical, so only the anlvsis of running speeds is presented.

The mean running speeds for each drug dosage $(0,5$, or $20 \mathrm{mg} / \mathrm{kg}$ ) are $0.808,1.080$, and 1.102 , respectively. The mean number of avoidance responses for the three drug dosages were $51.74,58.26$, and 58.37, respectively. The correlation between running speeds and mean number of avoidance responses per trial $=.98$. The two dosage levels of magnesium pemoline did not differ in their effects on running speed $(p<.20)$, but both dosage levels produced running speeds which differ significantly from the tragacanth controls $(p<.01)$.

Inspection of the data revealed that the $C S$ by Trials interaction was produced by higher mean running speeds during the first three blocks of trials for Ss who received the buzzer CS. The effect disappeared by the fourth day.

\section{DISCUSSION}

The failure to find a significant Drug by CS interaction is inconsistent with the Beach \& Kimble (1967) hypothesis that the effects of magnesium pemoline on response latencies during avoidance conditioning is an artifact of drug-induced increased responsiveness to a buzzer CS. Based upon the results of the present study magnesium pemoline appears to produce higher running speeds for all Ss on all days of acquisition training of an avoidance response.

Two additional characteristics of the data are of interest. First, the failure to find any differences as a function of the time duration between drug injection and start of conditioning suggests that the drug-induced changes occur within $30 \mathrm{~min}$ after injection and persist for at least $60 \mathrm{~min}$. Second, the failure to find behavioral differences related to the different dosages used, $5 \mathrm{vs} 20 \mathrm{mg} / \mathrm{kg}$, suggests that the lesser amount of drug is sufficient to produce the changes and that additional 


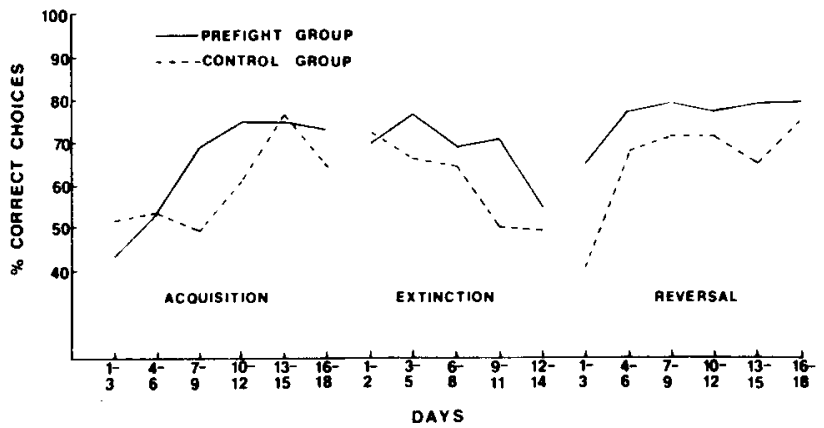

Fig. 1. Mean percentages of correct choices in the Control and Prefight groups on successive blocks of days.

one followed with the Prefight Ss, except that Control Ss were given no prefight in the start box and instead were detained for a 7-sec period before the start box door was raised.

\section{RESULTS}

Choice data and latencies were subjected to factorial analyses of variance, performed on successive blocks of six days, followed up by individual tests. Analyses of the free choices incorporated three factors: Prefight (absent vs present), Side of Reinforcement (left vs right), and Trials (Trial 1 vs Trial 2). Analyses of the latencies were based on all four latencies recorded each day and included a fourth factor, Reinforcement, allowing for a comparison of latencies of reinforced and nonreinforced choices.

The choice data plotted in Fig. 1 show that both the Control group and the Prefight group acquired a preference for the aggression-rewarded side of the maze, both during acquisition and reversal. The average percentages of correct choices during the last six days of acquisition were $71 \%$ and $74 \%$ for the Control and Prefight $\mathrm{Ss}$, respectively. The percentages are significantly above chance level $(p<.05$, Controls; $\mathrm{p}<.05$, Prefight group; $\mathrm{p}<.005$, the two groups combined). The corresponding percentages during the last six days of the reversal period were $71 \%$ and $79 \%(\mathrm{p}<.02$, Controls; $p<.01$, Prefight group; $p<.0005$, the two groups combined). The latency data also showed a significant reinforcement effect, the latencies of correct choices being clearly shorter than those of incorrect choices $(\mathrm{p}<.005$, Days 13-18, acquisition; $p<.0005$, Days 13-18, reversal).

A comparison of the Prefight group with the Controls indicated that the choice performance of the former tended to be superior, as shown in Fig. 1. The difference between the two groups was found to be significant early in acquisition (Days $7-12, p<.05$ ), late in extinction (Days 9-14, p<.05), and again early in reversal (Days $1-6, p<.05$ ). The latency data showed no significant differences between the two groups.

A final set of results revealed unexpectedly a daily recurring facilitation effect: The choice data showed an increase in the percentage of correct choices on the second free trial as compared to the first free trial. During acquisition the percentage of correct free choices (computed for the total sample) increased from $58 \%$ on Trial 1 to $70 \%$ on Trial 2 on Days $7-12(\mathrm{p}<.005)$, and from $69 \%$ to $76 \%$ on Days $13-18$ [not significant $(\mathrm{p}<.25)$ although in the same direction]. The latency data for these same periods revealed a corresponding, significant Trial by Reinforcement interaction resulting from the fact that the difference in latency between correct and incorrect choices, already noted above, was larger on the last two choices than on the first two choices $(\mathrm{p}<.005$, Days $7-12 ; p<.02$, Days $13-18$ ). The same patterns of choices and latencies were obtained during reversal learning, and the $p$ values of all four corresponding significance tests were below .005 .

The results clearly show that the opportunity to fight functioned as a reinforcer in the present experiment. Furthermore, extinction as well as reversal of the location of the reinforcer produced effects comparable to those observed with other reinforcers such as food and water.

Both the effects of the prefight manipulation and the trial effect indicate that the preference for aggression will be more clearly evident when $\mathrm{S}$ has undergone a prior "warm-up" experience. In fact, on trials preceded by neither an earlier trial nor a prefight (in other words, on first trials in the Control group), preference for the aggression-rewarded side of the maze is rather slight: $67 \%$ and $55 \%$ on Days $13-18$ of acquisition and reversal, respectively (neither value differs significantly from $50 \%$ ). On the other hand, on trials preceded by both an earlier trial and a prefight (that is, on second trials in the Prefight group), preference for the aggression-rewarded side of the maze is clear cut: $77 \%$ and $96 \%$, respectively, on Days 13-18 of acquisition and reversal. The warm-up effects may be due to the fact that just prior to their occurrence Ss had been engaged in aggressive behavior (in the goal box following the first correct choice, and in the start box if $S$ was in the Prefight condition). In that case the results would be consistent with Lagerspetz's notion that $S$ will show a clear preference for aggression only when aroused by prior aggression. The data, however, are not decisive on this point. It is possible that factors other than aggression contributed to the observed facilitation. For example, merely negotiating the maze might facilitate performance on the next trial, and thus contribute to the observed trial effect. Whatever the nature and number of mechanisms mediating warm-up phenomena, their occurrence suggests the importance of exogenous factors for the activation of a preference for aggression. The present results thus do not conform to a strictly endogenous view of aggresssive motivation.

\section{REFERENCES}

LAGERSPETZ, K. Studies on the aggressive behaviour of mice. Helsinki: Suomalainen Tiedeakatemia, 1964

SCOTT, J. P. Aggression. Chicago: University of Chicago Press, 1958.

SCOTT, J. P. Agonistic behavior of mice and rats: A review. American Zoologist, 1966, 6, 683-701.

1. Presently at St. Olaf College, North

\section{(Continued from page 103)}

dosages fail to produce greater change. This finding suggests that whatever CNS changes are produced by magnesium pemoline are "triggered" by the drug, and function in an all-or-none fashion. This is, admittedly, a speculative hypothesis, and further research of a parametric nature will be required to verify or refute it.

\section{REFERENCES}

BEACH, G., \& KIMBLE, D. P. Activity and responsivity in rats after magnesium pemoline injections. Science, 1967, 155, 698-701.
GLASKY, A. J., \& SIMON, L. N. Magnesium pemoline: Enhancement of brain RNA polymerases. Science, 1966, 151, 702-703.

PLOTNIKOFF, N. Magnesium pemoline: Enhancement of learning and memory of a conditioned avoidance response. Science, 1966, 151, 703-704.

\section{NOTES}

1. The authors wish to express appreciation to Abbott Laboratories for supplying the magnesium pemoline used in the present study.

2. Present address: Department of Psychology, University of Kentucky, Lexington, Ky. 40506. 